\title{
Selecting deep brain stimulation or infusion therapies in advanced Parkinson's disease: an evidence-based review
}

\author{
Jens Volkmann • Alberto Albanese • Angelo Antonini - K. Ray Chaudhuri • Carl E. Clarke • \\ Rob M. A. de Bie · Günther Deuschl · Karla Eggert · Jean-Luc Houeto · Jaime Kulisevsky • \\ Dag Nyholm • Per Odin · Karen Østergaard - Werner Poewe • Pierre Pollak · Jose Martin Rabey • \\ Olivier Rascol • Evzen Ruzicka • Michael Samuel • Hans Speelman • Olof Sydow • \\ Francesc Valldeoriola $\cdot$ Chris van der Linden $\cdot$ Wolfgang Oertel
}

Received: 18 October 2012 / Accepted: 10 December 2012/Published online: 5 January 2013

(C) The Author(s) 2012. This article is published with open access at Springerlink.com

\begin{abstract}
Motor complications in Parkinson's disease (PD) result from the short half-life and irregular plasma fluctuations of oral levodopa. When strategies of providing more continuous dopaminergic stimulation by adjusting oral medication fail, patients may be candidates for one of three device-aided therapies: deep brain stimulation (DBS), continuous subcutaneous apomorphine infusion, or continuous duodenal/jejunal levodopa/ carbidopa pump infusion (DLI). These therapies differ in their invasiveness, side-effect profile, and the need for
\end{abstract}

J. Volkmann $(\bowtie)$

Department of Neurology, University Clinic of Würzburg,

Josef-Schneider-Str. 11, 97080 Würzburg, Germany

e-mail: volkmann_j@klinik.uni-wuerzburg.de

\section{A. Albanese}

Dipartimento di Neuroscienze Cliniche, Istituto Nazionale Neurologico Carlo Besta, Università Cattolica del Sacro Cuore, Milan, Italy

\section{A. Antonini \\ IRCCS San Camillo, Venice, Italy}

K. R. Chaudhuri · M. Samuel

Department of Neurology, King's College Hospital, London, UK

C. E. Clarke

Medical and Dental School, University of Birmingham,

Birmingham, UK

\section{R. M. A. de Bie}

Department of Neurology, Academic Medical Center,

Amsterdam, The Netherlands

G. Deuschl

Department of Neurology, Christian-Albrechts-University,

Kiel, Germany nursing care. So far, very few comparative studies have evaluated the efficacy of the three device-aided therapies for specific motor problems in advanced PD. As a result, neurologists currently lack guidance as to which therapy could be most appropriate for a particular PD patient. A group of experts knowledgeable in all three therapies reviewed the currently available literature for each treatment and identified variables of clinical relevance for choosing one of the three options such as type of motor problems, age, and cognitive and psychiatric

\section{K. Eggert · W. Oertel}

Department of Neurology, Philipps-University Marburg,

Marburg, Germany

J.-L. Houeto

Service de Neurologie, CIC 802, CHU de Poitiers,

Poitiers, France

J. Kulisevsky

Movement Disorders Unit, Neurology Department,

Sant Pau Hospital, Universitat Autònoma de Barcelona and CIBERNED, Barcelona, Spain

D. Nyholm

Department of Neuroscience, Neurology,

Uppsala University, Uppsala, Sweden

P. Odin

Department of Neurology, Klinikum-Bremerhaven,

Bremerhaven, Germany

K. Østergaard

Department of Neurology, Aarhus University Hospital,

Aarhus, Denmark

W. Poewe

Clinical Department of Neurology,

Innsbruck Medical University, Innsbruck, Austria 
status. For each scenario, pragmatic and (if available) evidence-based recommendations are provided as to which patients could be candidates for either DBS, DLI, or subcutaneous apomorphine.

Keywords Apomorphine - Deep brain stimulation . Duodenal levodopa infusion · Parkinson's disease

\section{Background and aims}

The management of Parkinson's disease (PD) becomes challenging when motor complications (e.g., motor fluctuations including loss of medication effects such as "wearing off", end-of-dose effect, "sudden off", and dyskinesia) can no longer be controlled adequately by changes in oral medication. Gradual worsening of these disabling phenomena has a significant impact on daily activities and social participation, important determinants of quality of life (QoL) [1-3]. If conventional drug therapy fails, three device-aided therapies can reduce the burden of motor complications in advanced PD patients: (1) apomorphine, administered subcutaneously via daytime intermittent bolus injection or continuous pump infusion; (2) continuous duodenal/jejunal levodopa/carbidopa pump infusion (DLI), administered via gastrojejunostomy; (3) deep brain stimulation (DBS)-bilateral stimulation of the subthalamic nucleus (STN), globus pallidus (GPi) or ventral intermediate thalamic nucleus (Vim). So far, no guidelines exist concerning the decisionmaking regarding which therapy should be chosen for individual patients.

Therefore, a group of PD experts experienced in these therapies reviewed the literature in order to provide neurologists with an evidence-based overview of the most appropriate therapy for advanced motor symptoms in patients with PD.

\section{P. Pollak}

Service de Neurologie, Hòpitaux Universitaires de Genève, Genève, Switzerland

\section{J. M. Rabey}

Department of Neurology, Assaf Harofeh Medical Center,

Tel Aviv University, Zerifin, Israel

\section{O. Rascol}

Departments of Clinical Pharmacology and Neurology, INSERM CIC9302 and UMR 825, University Hospital and University of Toulouse III, Toulouse, France

E. Ruzicka

Department of Neurology, 1st Medical Faculty,

Charles University, Prague, Czech Republic

\section{Methods}

A literature search (MEDLINE, EMBASE) was conducted in May of 2009 to identify relevant studies evaluating: STN- or GPi-DBS, subcutaneous apomorphine (intermittent injections or continuous infusion), or continuous DLI. Only studies assessing the chronic use of each treatment in $\geq 10$ patients were included; all reviews, meta-analyses, and experimental studies were excluded. Studies identified were graded according to European Federation of Neurological Societies (EFNS) Guidelines [4], from class I (highest quality) to class IV (lowest quality).

A consensus group met on June 26-27, 2009 in Marburg, Germany. All members were experts in PD treatment, with experience in at least two device-aided procedures. The impact of certain clinical parameters on the outcome and the risks of each therapy were discussed extensively. As it was generally agreed that there is currently insufficient evidence to formulate definitive conclusions and recommendations, pragmatic suggestions were formulated and discussed until consensus was reached. During the discussion process and manuscript drafting, the available evidence was updated to May 2012.

\section{The available evidence}

Numerous DBS studies were identified, therefore only classes I-III were included. Few studies of any class were found for apomorphine and DLI, necessitating the inclusion of relevant class IV studies. Table 1 outlines key characteristics and clinical outcomes observed in the available class I and II studies. In total, 53 studies were identified for DBS (published between 2000 and 2010: six class I [5-10], four class II [11-14], 43 class III [15-57]; total number of patients, $n=3,291$ ), 16 for apomorphine (1993-2012: no class I or II, six class III [15, 33, 40, 58-60], ten class IV [61-70]; $n=612$ ) and 12 for DLI (1998-2012: two class I [71, 72], one class II [73],

H. Speelman

Department of Neurology, University of Amsterdam,

Amsterdam, The Netherlands

O. Sydow

Department of Neurology, Karolinska University Hospital,

Stockholm, Sweden

F. Valldeoriola

Neurology Services, Movement Disorders Unit,

Hospital Clinic i Provincial, Barcelona, Spain

C. van der Linden

Department of Neurology, AZ Sint Lucas,

Ghent, Belgium 


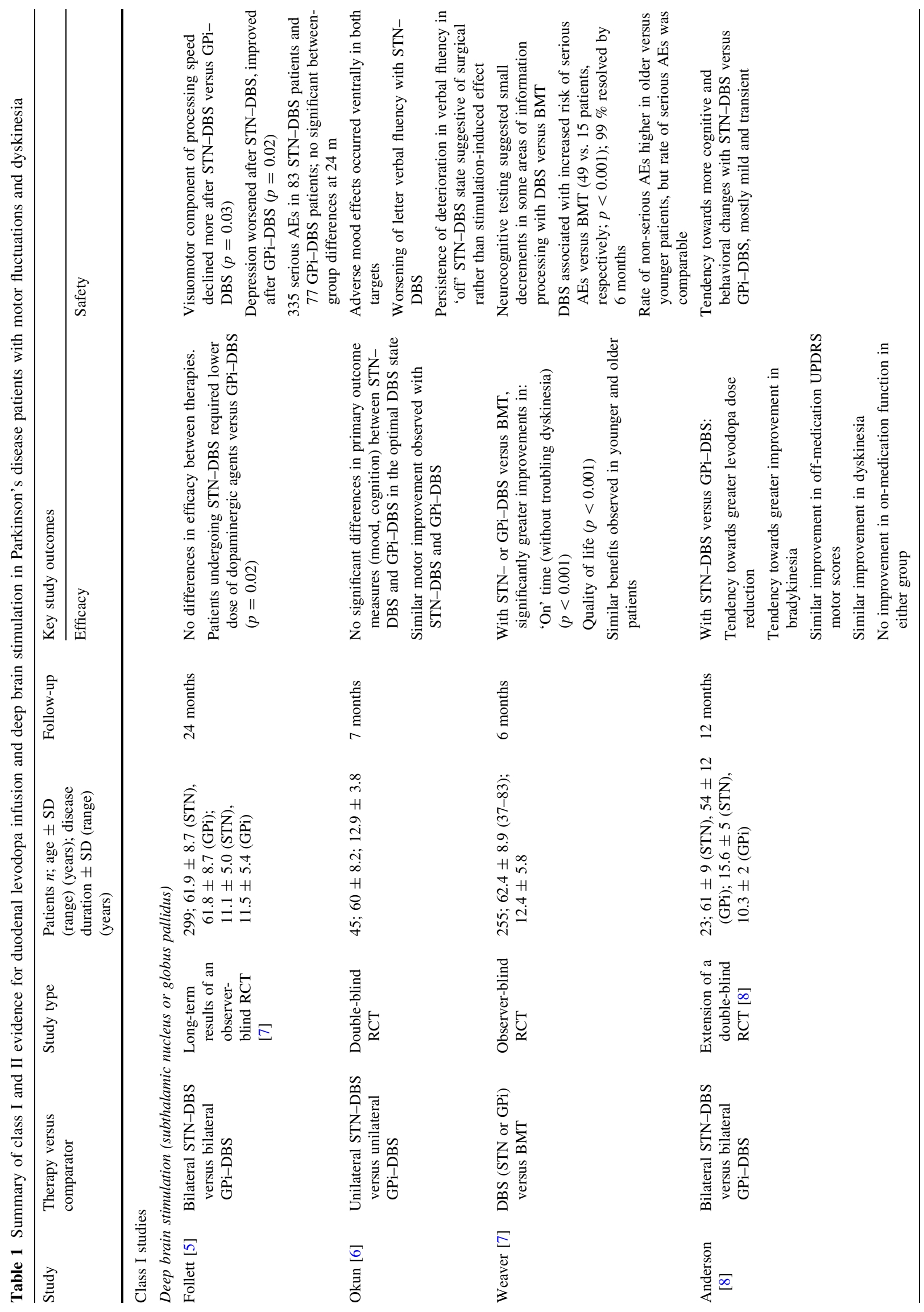




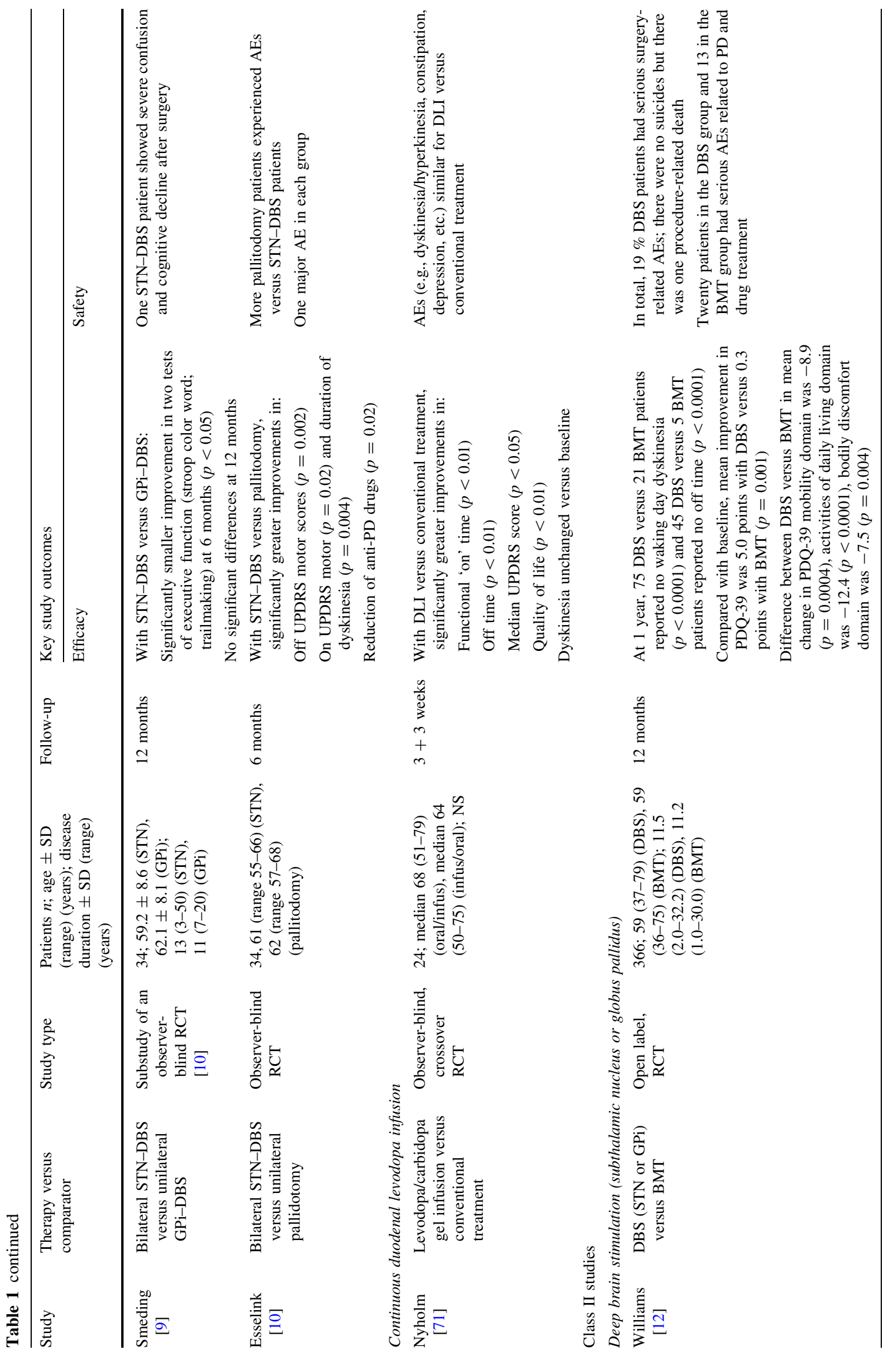




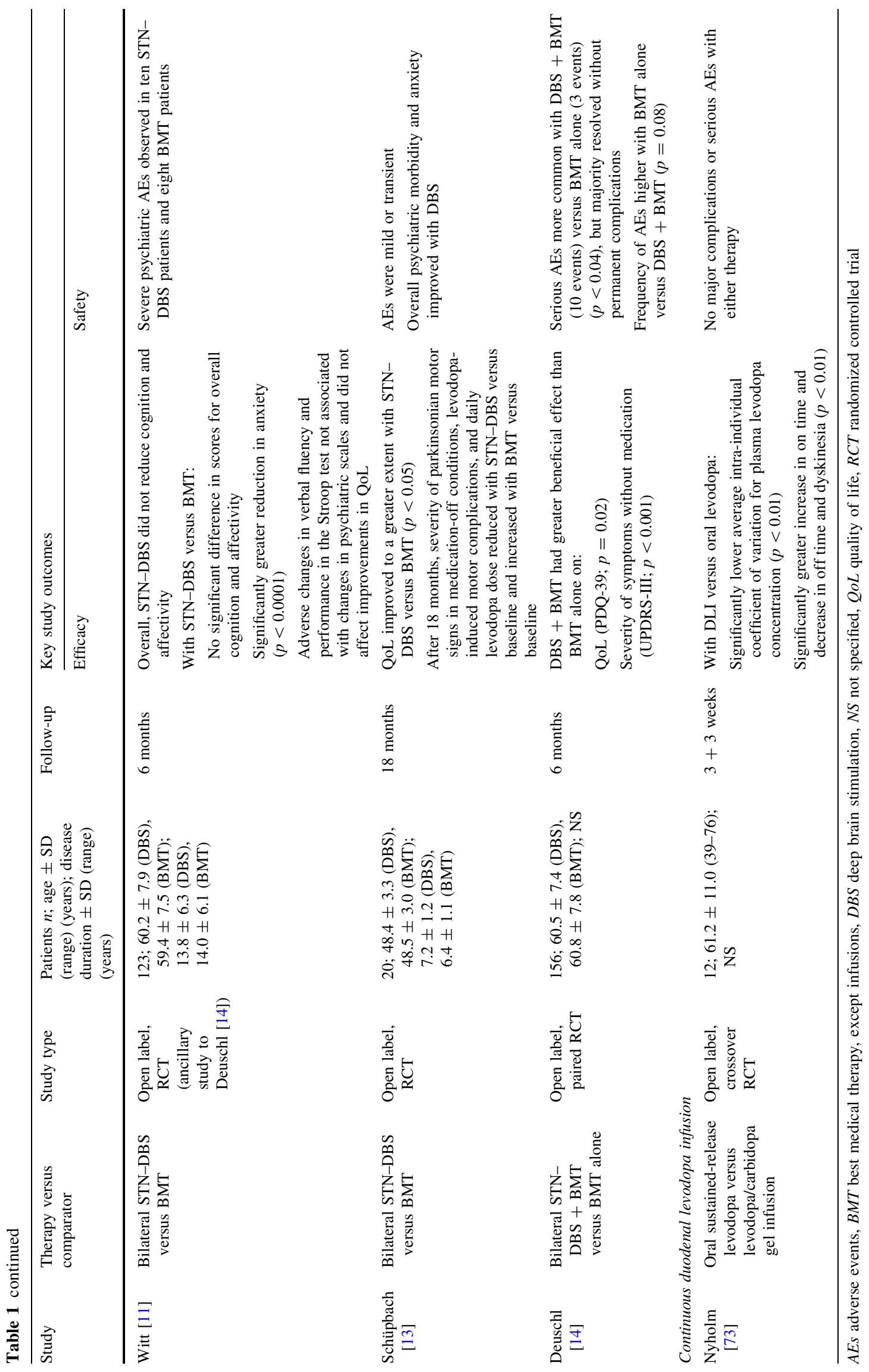


nine class IV [61, 74-81]; $n=439$ ). Table 2 outlines relevant studies that evaluated the effects of each therapy on the clinical parameters determined by the consensus group, discussed in Sects. 1 and 2 below.

The current evidence best supports DBS, with more well-designed, i.e., prospective, randomized controlled trials (RCTs) compared to infusion therapies. In addition, class I and II studies directly compared DBS with best medical (pharmacological) treatment (BMT), which sometimes included apomorphine (e.g., [12]). In contrast, few prospective RCTs exist for DLI and none for apomorphine; most were non-randomized, uncontrolled, open-label, retrospective, generally small and with short follow-up, or were case studies. Nevertheless, these data provide clinically useful information. Five studies directly compared any of the three therapies [15, 33, 40, 61, 74], only one compared all three [61]. Even more importantly, treatment decisions in a clinical setting are often influenced by individual factors that may represent exclusion criteria in controlled studies (e.g., older age, neuropsychiatric comorbidity, frailty), exemplifying the need to include naturalistic studies with scenarios that are excluded from RCTs.

\section{Managing the target motor symptoms of PD}

Is any device-aided therapy preferable regarding efficacy in managing target motor symptoms of PD?

\section{Severity of off-period symptoms}

The impact of DBS on off-period symptoms is typically analyzed in an artificial situation, which does not reflect the clinical practice of treating patients continuously with an optimized combination of stimulation and medication. The observed improvement in off-period symptoms (UPDRS motor score) induced by STN-DBS ranged between 30 and $60 \%$ in larger trials. There was less and lower quality data on the impact of GPi-DBS, but it seemed to be around $30 \%$. Although apomorphine infusion or DLI have never been formally assessed for their impact on off-period symptoms in a setting comparable to DBS studies (they provide continuous drug, so a levodopa challenge test would make little sense in their clinical evaluation), one would expect them to have an at least equivalent, if not short-term superior effect, if given in appropriate dosages.

\section{Motor fluctuations}

$D B S$ (STN and GPi) The reduction in daily off-time with DBS was variable and ranged between 30 and $100 \%$ (median 68\%). Each study demonstrated significant reductions in off-time. Similarly, increase in on-time without dyskinesia ranged from 47 to $138 \%$ (median $71 \%$ ). Apomorphine Data specifically addressing fluctuations are limited: overall reduction in off-time varied from 25 to $80 \%$, with lower values being reported more often (median $44 \%$ ). However, results were rarely recorded on a daily chart per hour, making it difficult to assess the results' true value. Off-time reduction was restricted to the daytime; nocturnal akinetic periods were not addressed. An increase in on-time without dyskinesia was rarely reported, ranging from 8 to $85 \%$ (median $40 \%$ ). DLI Off-periods were reduced by $40-80 \%$ (daytime off only as DLI was mostly discontinued at night). One study reported increase in on-time without dyskinesia $(88 \%)$.

\section{Dyskinesia}

$D B S$ (STN and $G P i$ ) Dyskinesia reduction ranged from 70 to $100 \%$. DBS also reduced dyskinesia severity by up to $83 \%$. Dyskinesia benefits were consistently reported. In STN-DBS, dyskinesia alleviation was related to the reduction of dopaminergic medication, not directly attributable to neurostimulation itself. Apomorphine Apomorphine had a variable effect on dyskinesia, ranging from no reduction to $70 \%$ reduction (greatest reductions in older studies). Dyskinesia benefits depended on oral levodopa withdrawal and mostly referred to patients on oral levodopa monotherapy before infusion. DLI Dyskinesia time was reduced by $60-90 \%$. This was not related to total daily levodopa dosage reductions, but to the more continuous dose distribution.

\section{Tremor}

DBS (STN and GPi) DBS had a beneficial effect on tremor (and bradykinesia and rigidity, also cardinal motor PD symptoms). Apomorphine and DLI The effects of either therapy on tremor were not clearly addressed.

\section{Conclusions}

In general, more evidence exists for the efficacy of DBS on motor fluctuations and dyskinesia versus DLI and apomorphine. Consistent results with DBS indicated its efficacy at reducing off-period motor symptoms and increasing on-time without dyskinesia. Apomorphine is likely effective at reducing daytime motor fluctuations and has a variable effect on dyskinesia, but existing evidence is too poor to permit firm conclusions. Off-time reduction with DLI is limited to the daytime; some nighttime effects have been reported [82]. Although sometimes practiced, there are concerns about the safety of 24-h dopaminergic 


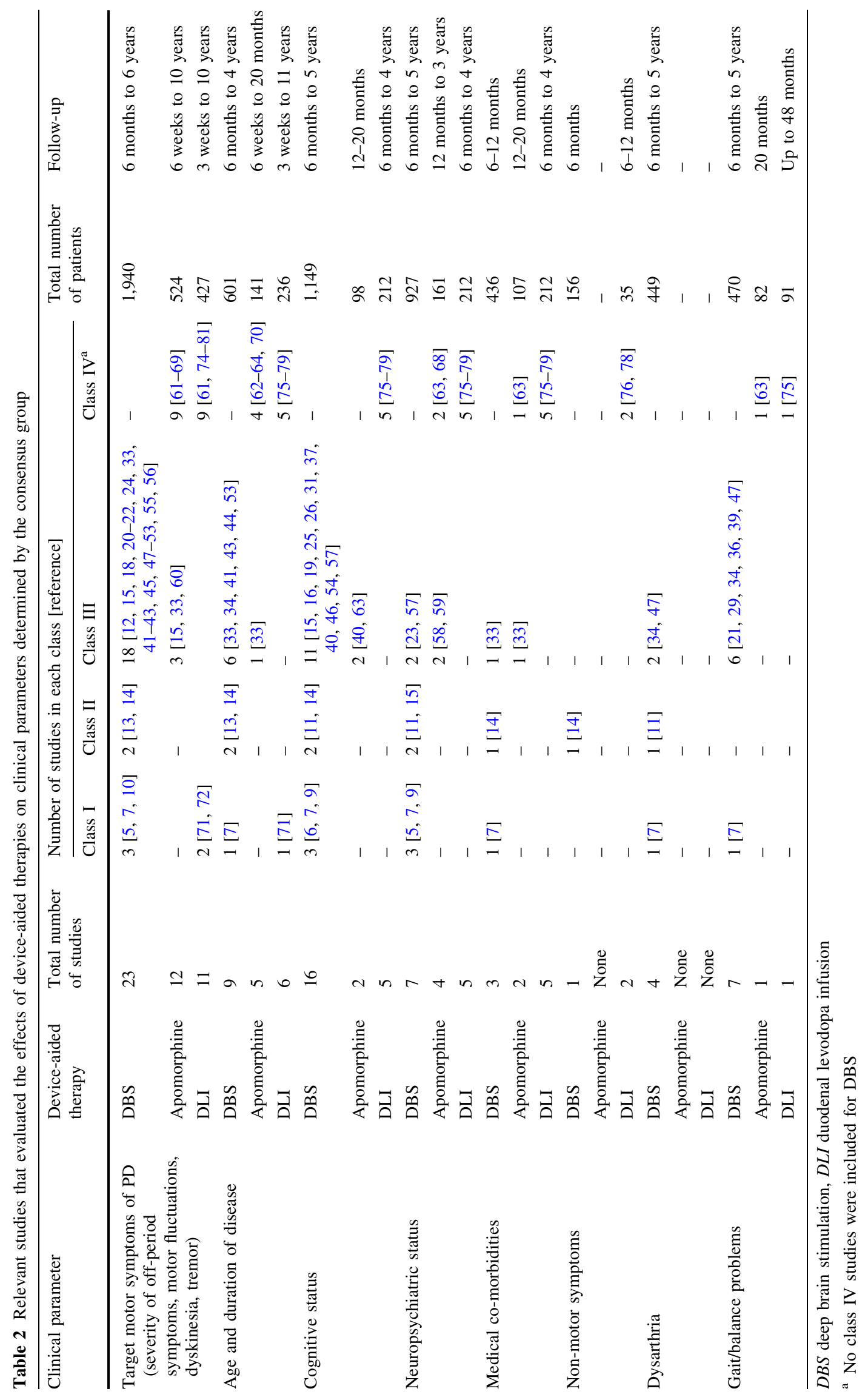


infusion therapy and uncertainty regarding nighttime dose adjustments required. Preliminary data suggest that DLI has a strong beneficial effect on dyskinesia [72], but lack of formal evidence precludes firm conclusions. For disabling tremor, DBS can be effective even if tremor was unresponsive to levodopa or other oral dopaminergic drugs.

What patient-related factors may influence the choice of therapy?

\section{Age and duration of disease}

Does the patient's age or duration of PD prior to treatment affect the outcome of therapy? If so, can it be used as a predictor of response?

$D B S$ Younger age predicts a more favorable response to bilateral STN-DBS regarding motor and QoL improvement. There are concerns that progression of axial motor signs and emerging dementia may counteract improved activities of daily living (ADL) after STN-DBS in older patients ( $>70$ years). However, in a study where $25 \%$ of patients were $>70$ years [7], there was comparable benefit in younger and older patients regarding on-time without dyskinesia and off-period UPDRS motor scores. There was a higher risk of non-serious adverse events (AEs) in older patients, but no difference between older and younger patients in the rate or type of serious AEs [7]. A large series did not observe a greater risk of bleeding in elderly patients [83].

Regarding disease duration, reliable long-term results (up to 8 years) have been observed in patients with PD for a mean of 15 years before surgery, but the risk of evolving dementia or gait problems appears higher with a longer disease duration. However, the "window of opportunity" for STN-DBS may open earlier, when fluctuations and dyskinesia emerge and start to impact on ADL in younger patients [13].

Apomorphine Apomorphine was effective in older patients (up to 85 years) with a long disease duration. No relationship between age and disease duration on the outcome of treatment was observed. No studies stratified AEs by age.

DLI DLI can be effective in patients of all ages and with a long disease duration. DLI appears an effective last-line therapy for PD motor complications, with suggestions to prefer it over other device-assisted therapies in older, frail patients because of better tolerability.

\section{Conclusions}

While STN-DBS can confer improvements in motor symptoms in older patients ( $>70$ years), it may provide greater benefits in younger patients regarding ADL and
QoL, with a seemingly lower risk of AEs. STN-DBS should not be considered a treatment of last resort as better results might be obtained in younger patients with a shorter duration of motor complications [84]. The durability of the treatment effect, which can be counteracted by the evolution of axial motor symptoms and cognitive decline [85], should be discussed with older surgical candidates. The efficacy of apomorphine on motor symptoms does not seem to depend on age or disease duration, but there are insufficient and contradictory data [70] to conclude on safety in older patients, in particular the risk of psychosis and confusional states. There is no evidence of an age-related decline with DLI, which seems to be well tolerated, even in older patients with very advanced PD including some cognitive decline.

\section{Cognitive and neuropsychiatric status}

Cognitive status What effect does each therapy have on the patient's cognitive status? Can this be used to recommend a treatment?

$D B S$ No safety data exist in patients with co-existing dementia and active psychiatric symptoms at baseline, as they are usually excluded from DBS studies. In patients with normal neuropsychological testing before surgery, some frontal executive function measures (e.g., verbal fluency) decreased with DBS, but no changes in global cognitive scores were found. No significant differences were seen with stimulation 'on' or 'off' $[11,57]$, so the observed effects on frontal executive function are less likely caused by neurostimulation per se, but may result from surgical aspects (e.g., microlesional effect at the STN target or the trajectories of the electrodes through the frontal white or deep gray matter). Notably, small but significant deterioration in frontal executive scores did not affect daily functions or QoL. Apomorphine One study showed no cognitive changes, while the other noted a trend towards impaired cognitive function after apomorphine challenge, with a confused state in $17 \%$ of patients (only half the patients completed the study). DLI In general, no definite conclusions could be made due to lack of study data.

\section{Conclusions}

STN-DBS seems cognitively safe in patients with normal age-related cognitive testing at the time of DBS. However, special care should be taken in those on a clinical course suggestive of imminent cognitive decline. It is not known whether decrements in frontal-executive functions caused by STN-DBS could aggravate natural PD-related cognitive dysfunction in the long term. Clinically recognized dementia (DSM IV) is a contraindication for DBS. Baseline 
characteristics (e.g., age at onset, presence of axial 'on' symptoms) may individually predict postoperative cognitive decline [86], and should be weighed against possible motor benefits. Few or inconclusive data exist on the cognitive safety of apomorphine or DLI but, except for the risk of acute confusional states with dopaminergic therapy, they should not impact on the natural evolution of dementia in PD.

\section{Neuropsychiatric status}

Does the patient's neuropsychiatric status before treatment affect outcomes? Can any therapy be recommended in patients with pre-existing neuropsychiatric problems?

$D B S$ On average, depressive mood ratings improved after STN-DBS. However, the risk of aggravation increased in patients diagnosed with depression at baseline. Suicide risk increased within the first year after STN-DBS, along with other impulsive behavioral disorders, but returned to baseline after 3 years. Anxiety improved in most patients. Apathy improved with acute 'on'/'off' stimulation, but 12-25\% of chronic STN-DBS patients developed apathy after extensive reduction of dopaminergic medication. Conflicting data exist on the effect of STN-DBS in patients with impulse control disorders or dopa dysregulation syndrome, with aggravation in some and marked improvements in others, if dopaminergic medication withdrawal was tolerated. Most neuropsychiatric problems were generally reported during the adjustment period of medication and stimulation and tended to disappear within the first 6 months.

Apomorphine There was a moderate improvement in mood and anxiety, but frequent induction or aggravation of visual hallucinations, confusional states, hypersexuality and paranoid psychosis. A 24-h infusion is considered unsafe because of the risk of exacerbating psychiatric complications. DLI Few neuropsychiatric AEs were observed, with some improvements in psychiatric symptoms (e.g., depression, anxiety, delusions, hallucinations) in patients with mild-moderate cognitive impairment and previous psychosis. The most likely reason is the change from oral antiparkinsonian polypharmacy to levodopa monotherapy.

\section{Conclusions}

For STN-DBS, strong evidence supports a favorable impact on mild-moderate depression and anxiety after 6-12 months, while weaker evidence suggests possible deleterious effects on apathy, psychosis, impulsivity and emotional processing. Conflicting data exist regarding effects of STNDBS in patients with impulse control disorders or dopa dysregulation syndrome. Favorable outcomes may require withdrawal of dopaminergic medication. Ongoing psychotic or severe depressive episodes (with or without suicidal ideation) are DBS contraindications, but may be treated and DBS performed after remission. Fewer reports exist of neuropsychiatric complications with GPi-DBS, possibly reflecting publication bias.

Based on limited evidence, apomorphine may improve mood and anxiety but is associated with a risk of psychosis, confusion and disinhibited behavior. Clinical experience suggests caution in patients with impulse control disorders. The available data for DLI do not allow firm conclusions on neuropsychiatric safety, but open label data suggest it may be best tolerated of all three options in patients with a history of psychosis. No evidence exists to comment on ongoing psychosis or impulse control disorders. It is recommended that neuropsychiatric assessment is carried out before any device-aided therapy and that patients with previous psychiatric history receive post-treatment neuropsychiatric surveillance.

\section{Medical co-morbidities}

Do any medical co-morbidities preclude a particular treatment?

Little evidence relates to medical co-morbidities, mainly because studies excluded affected patients. DBS Medical contraindications for DBS apply in general for awake stereotactic neurosurgery. Severe brain atrophy or lesions interfering with trajectory planning are normally considered a surgical contraindication. Anticoagulation or cardiac devices are not strict contraindications, but complicate surgery. Apomorphine Diabetes mellitus, if the patient has wound healing, cellulitis or skin problems, may be problematic. DLI Previous abdominal surgery may not allow the placing of a gastrojejunostomy and constitutes a contraindication. Inflammatory demyelinating polyneuropathy is a possible severe $\mathrm{AE}$, but the impact on preexisting polyneuropathy has not been established. The weight of the pump may be a relative contraindication or burden in frail patients. Patients should be advised about their individual risks and counseled as to whether they outweigh the expected benefits of any device-aided therapy.

\section{Non-motor symptoms}

What effect does each therapy have on non-motor symptoms (NMS) (e.g., sleep problems, pain, loss of energy, etc.), which many patients regard as having a greater impact than motor disorders [87]? Is it possible to choose a therapy according to the patient's NMS?

Few studies have assessed the impact on NMS. DBS provides a 24-h effect; a beneficial effect on sleep is indirectly supported by significantly increased sleep 
duration versus BMT. DLI significantly improved several NMS domains, i.e. cardiovascular, sleep/fatigue, attention/ memory, gastrointestinal, urinary, miscellaneous (including pain and dribbling). Because few studies have assessed these factors, NMS should not be a decisive reason for recommending a therapy.

\section{Presence of dysarthria}

Will any treatment have an impact on speech (dysarthria) with long-term use?

$D B S$ Generally, DBS did not or only transiently improve off-period scores of speech or swallowing. Moreover, dysarthria was the most frequent non-serious AE. Apomorphine and DLI No data exist, but clinical observation suggests they are not likely to increase the risk of dysarthria.

\section{Conclusions}

STN-DBS may cause mild-moderate impairments in speech (up to $10 \%$ of patients), whereas any mild beneficial effects do not seem to last beyond 12 months. Impairments are not always reversible or solved by adjusting stimulation parameters. The causes of dysarthria after DBS are multifactorial, including unmasking of PD-related speech problems with excessive drug withdrawal, stimulation-induced speech problems by inadvertent current spread to the internal capsule, and progression of axial motor symptoms in the long term. DBS is not recommended for patients with preexisting significant speech or swallowing difficulties. Speech is less likely to worsen with apomorphine or DLI, although no supporting published data exist.

\section{Presence of gait and balance problems}

What effect does each therapy have on gait, instability and the risk of falls?

Note that some studies have evaluated gait kinematics, but are not included because we aim to discuss clinical usefulness (i.e. gait in a daily setting). DBS Falls or gait disturbance have been reported as AEs of STN-DBS. This contrasts with significant short- and long-term improvements in off-period postural instability and gait disorder (PIGD) UPDRS subscores, as well as significant improvements in freezing of gait, gait parameters and balance. A worsening in on-period axial subscores was reported in patients $>70$ years, especially those with preoperative gait difficulties [44]. Apomorphine A significant improvement in gait imbalance has been demonstrated (one study) [63]. DLI DLI improved gait disorders (freezing, festination, postural instability) in almost two-thirds of patients in one study [75].

\section{Conclusions}

Overall, significant gait and balance improvements have been demonstrated after STN-DBS. The benefits may be greater in younger patients, closely linked to the levodoparesponsiveness of axial motor symptoms before surgery. An increased risk of falling has been reported, but it is unclear whether this relates to detrimental effects of DBS per se, to the transitional period of optimizing the interplay of DBS and medication following surgery, or paradoxically to an increased mobility in patients with preexisting postural instability. Physicians need to review the risk of falling with patients before recommending DBS. Any beneficial effects of STN-DBS on gait, posture and postural stability may diminish with the natural disease progression. STN-DBS may not match the benefits of levodopa on axial symptoms in older patients, thus leading to increased gait or balance problems with postoperative withdrawal of dopaminergic drug. Patients with levodoparesistant postural problems before surgery are at particular risk of falls after DBS. Apomorphine and DLI may have positive effects on levodopa-sensitive gait and balance problems or on dyskinesia-related problems, but only weak supporting evidence exist.

\section{Recommendations when advising patients regarding treatment}

Managing advanced PD is complex. Treatment needs to consider motor and non-motor symptoms as well as several other individual factors, requiring a tailored approach for each patient. Currently, no direct comparative data exist to support the use of one device-aided therapy over another. It is doubtful this evidence will be generated due to the complexity and the lack of industry drive to design trials of direct comparison.

Each therapy has generated efficacy data for off motor symptoms, on-off fluctuations and dyskinesia, although the level of evidence is currently highest for DBS. However, in day-to-day clinical practice, therapeutic decisions often need to be made in patients who would not fit the strict inclusion/exclusion criteria of clinical trials; other factors such as the severity of cognitive, psychiatric, speech, balance and general medical conditions also require scrutiny. A multidisciplinary approach towards evaluating the contribution of these factors on impaired QoL is highly recommended. A useful stepwise guide would initially involve a careful workup to address the presence of disabling motor fluctuations, dyskinesia and tremor, levodopa responsiveness, general medical condition and cognitive and neuropsychiatric status. Determination of absolute and relative contraindications should follow, as some patients 
will only be suitable for a single therapy while others will have greater choice. If they are eligible for several therapies, an individual risk-benefit assessment should then address the key question, which therapy is most likely to restore daily functions and QoL? Patient preference forms a significant part of the decision-making process, and identifies: the PD aspects that have the most impact on QoL; lifestyle limitations and personalized social stigma due to a device's visibility; a patient's ability and desire to comply with device maintenance for long-term clinical benefit. It is important that neurologists discuss QoL and lifestyle needs with patients and caregivers, and provide advice regarding the potential impact of each therapy on their lives. Full practical therapeutic details should be provided, and patients should be aware of the frequency of follow-up that is essential for all therapies and the amount of daily nursing care required for apomorphine and DLI. It is important that patients realize that each therapy is reversible, so that if one becomes unsuitable, they have the option of trying another. Reimbursement issues may have to be considered in some countries.

Communicating this level of information is complex, requiring experience by a neurologist with a good understanding of all therapies, including the advantages, possible disadvantages and practical problems, taking into account limited comparative evidence. Although it can be time consuming, it is vital to allow patients and caregivers to make an informed decision as to the most appropriate therapy to meet their specific requirements.

Acknowledgments Editorial assistance for this manuscript was provided by Deborah Nock (DPP-Cordell Ltd), with full review, revisions and approval by all authors. The work was supported by an unrestricted educational grant of Medtronic Inc. to the German Competence Network on Parkinson's disease.

Conflicts of interest Jens Volkmann serves as a consultant to Abbott Pharmaceuticals (Duodopa) and Medtronic Inc. (DBS) and has received lecture fees from Medtronic Inc., St. Judes Inc (DBS) and Abbott (Duodopa). Alberto Albanese serves as a consultant to Abbott, Lundbeck, Medtronic and Merz. Angelo Antonini has received honoraria or payments for advisory boards from Abbot, Boehringer Ingelheim, Novartis, Lundbeck, UCB, Merck-Serono, GSK, GE Healthcare, Valeant. Carl E Clarke has received honoraria for lectures, travel expenses for conferences, and unrestricted educational grants from Abbott, Boehringer-Ingelheim, Britannia, GlaxoSmithKline, Medtronic, Novartis, Orion Pharma, Teva/Lundbeck, and UCB. Rob de Bie received financial support for a fellowship program from Medtronic, and has received research grants from ZonMw, Internationaal Parkinson Fonds, Prinses Beatrix Fonds, Michael J Fox Foundation, and Parkinson Vereniging. Günther Deuschl has received lecture fees from Orion, Lundbeck, Teva and Pfizer and has been serving as a consultant for TEVA. He received royalties from Thieme publishers. He is a government employee and he receives funding for his research through his institution from the German Research Council, the German Ministry of Education and Health and Medtronic. Karla Eggert served as a consultant to Abbott (previously Solvay) Pharmaceuticals (Duodopa) and has received lecture fees from Cephalon (Apomorphine) and Abbott/Solvay (Duodopa). Dag Nyholm serves as a consultant to Abbott (Duodopa), AstraZeneca and Sensidose $\mathrm{AB}$, and has received lecture fees from NordicInfu Care (apomorphine). Jean-Luc Houeto has received lecture fees from Medtronic Inc and Abbott Pharmaceuticals (Duodopa). Per Odin has received payment as consultant for Abbott and Cephalon, for expert testimonies for Abbott and for lectures from Abbott, Cephalon, Britannia and UCB. Karen Østergaard serves as a consultant to Medtronic Inc. (DBS) and has received lecture fees from Medtronic Inc. (DBS), Abbott (Duodopa), InfuCare (Apomorphine), GSK, Boehringer-Ingelheim, UCB, Orion Pharma and Lundbeck. Werner Poewe has received consultancy and lecture fees from Astra Zeneca, Teva, Novartis, GSK, Boehringer-Ingelheim, UCB, Orion Pharma and Merck Serono in relation to clinical drug development programmes for PD. Olivier Rascol serves as a consultant to Abbott, ADDEX, BIAL, Boehringer Ingelheim, GSK, IMPAX, Lundbeck, Merck-Serono, Novartis, TEVA, UCB. Evzen Ruzicka serves as a consultant to Medtronic Inc. (DBS). Michael Samuel has received: honoraria and sponsorship for educational meetings: Medtronic, UCB, St Jude Medical Inc, Boehrinher-Ingelheim; unrestricted educational grants from Solvay and Ipsen; other grants from Parkinson's UK, East Kent NHS Foundation Trust, King's College Hospital NHS Foundation Trust. Hans Speelman has received payment for lectures from Medtronic Inc. (DBS) and his institution also received consultancy fees from the same company. Francesc Valldeoriola has received honoraria for advice and lectures from Abbott Spain and Medtronic (Spain and Europe). Chris van der Linden has a consultancy agreement with Medtronic and has received travel sponsorship from Abbot. Wolfgang Oertel serves as a consultant to Abbott (previously Solvay) Pharmaceuticals (Duodopa) and Medtronic Inc. (DBS) and has received lecture fees from Medtronic Inc. (DBS), Cephalon (Apomorphine) and Abbott/Solvay (Duodopa). All other authors declared no conflicts of interest.

Open Access This article is distributed under the terms of the Creative Commons Attribution License which permits any use, distribution, and reproduction in any medium, provided the original author(s) and the source are credited.

\section{References}

1. Chapuis S, Ouchchane L, Metz O, Gerbaud L, Durif F (2005) Impact of the motor complications of Parkinson's disease on the quality of life. Mov Disord 20(2):224-230

2. Calne SM (2003) The psychosocial impact of late-stage Parkinson's disease. J Neurosci Nurs 35:306-313

3. Lökk J (2009) Reduced life-space of non-professional caregivers to Parkinson's disease patients with increased disease duration. Clin Neurol Neurosurg 111(7):583-587

4. Brainin M, Barnes M, Baron J-C, Gilhus NE, Hughes S, Selmaj $\mathrm{K}$, Waldemar G (2004) Guidance for the preparation of neurological management guidelines by EFNS scientific task forcesrevised recommendations 2004. Eur J Neurol 11:577-581

5. Follett K, Weaver F, Stern M, Hur K, Harris CL, Luo P et al (2010) Pallidal versus subthalamic deep-brain stimulation for Parkinson's disease. N Engl J Med 362(22):2077-2091

6. Okun M, Fernandez H, Wu SS, Kirsch-Darrow L, Bowers D, Bova F et al (2009) Cognition and mood in Parkinson's disease in subthalamic nucleus versus globus pallidus interna deep brain stimulation: the COMPARE Trial. Ann Neurol 65:586-595

7. Weaver F, Follett K, Stern M, Hur K, Harris C, Marks WJ Jr et al (2009) Bilateral deep brain stimulation vs best medical therapy 
for patients with advanced Parkinson's disease. JAMA 301(1): 63-73

8. Anderson V, Burchiel K, Hogarth P, Favre J, Hammerstad J (2005) Pallidal vs subthalamic nucleus deep brain stimulation in Parkinson disease. Arch Neurol 62:554-560

9. Smeding H, Esselink R, Schmand B, Koning-Haanstra M, Nijhuis I, Wijnalda EM, Speelman JD (2005) Unilateral pallidotomy versus bilateral subthalamic nucleus stimulation in PD. A comparison of neuropsychological effects. J Neurol 252:176-182

10. Esselink R, de Bie R, de Haan R, Lenders MW, Nijssen PC, Staal MJ, Smeding HM, Schuurman PR, Bosch DA, Speelman JD (2004) Unilateral pallidotomy versus bilateral subthalamic nucleus stimulation in PD. A randomized trial. Neurology 62:201-207

11. Witt K, Daniels C, Reiff J, Krack P, Volkmann J, Pinsker MO et al (2008) Neuropsychological and psychiatric changes after deep brain stimulation for Parkinson's disease: a randomised, multicentre study. Lancet Neurol 7:605-614

12. Williams A, Gill S, Varma T, Jenkinson C, Quinn N, Mitchell R, Scott R, Ives N, Rick C, Daniels J, Patel S, Wheatley K (2010) Deep brain stimulation plus best medical therapy versus best medical therapy alone for advanced Parkinson's disease (PD SURG trial): a randomised, open-label trial. Lancet Neurol 9(6):581-591

13. Schüpbach WM, Maltête D, Houeto JL, du Montcel ST, Mallet L, Welter ML et al (2007) Neurosurgery at an earlier stage of Parkinson disease: a randomized, controlled trial. Neurology 68(4):267-271

14. Deuschl G, Schade-Brittinger C, Krack P, Volkmann J, Schäfer H, Bötzel K et al (2006) A randomized trial of deep brain stimulation for Parkinson's disease. N Engl J Med 355:896-908

15. Antonini A, Isaias IU, Rodolfi G, Landi A, Natuzzi F, Siri C, Pezzoli G (2010) A 5-year prospective assessment of advanced Parkinson disease patients treated with subcutaneous apomorphine infusion or deep brain stimulation. J Neurol 258(4):579-585

16. Mikos A, Zahodne L, Okun M, Foote K, Bowers D (2010) Cognitive declines after unilateral deep brain stimulation surgery in Parkinson's disease: a controlled clinical study using reliable change, part II. Clin Neuropsychol 24(2):235-245

17. Taba H, Wu S, Foote KD, Hass CJ, Fernandez HH, Malaty IA, Rodriguez RL, Dai Y, Zeilman PR, Jacobson CE, Okun MS (2010) A closer look at unilateral versus bilateral deep brain stimulation: results of the National Institutes of Health COMPARE cohort. J Neurosurg 113:1124-1129

18. Moro E, Lozano AM, Pollak P, Agid Y, Rehncrona S, Volkmann $\mathrm{J}$ et al (2010) Long-term results of a multicenter study on subthalamic and pallidal stimulation in Parkinson's disease. Mov Disord 25(5):578-586

19. Zahodne L, Okun M, Foote K, Fernandez JJ, Rodriguez RL, Kirsch-Darrow L, Bowers D (2009) Cognitive declines one year after unilateral deep brain stimulation surgery in Parkinson's disease: a controlled study using reliable change. Clin Neuropsychol 23(3):385-405

20. Volkmann J, Albanese A, Kulisevsky J, Tornqvist A, Houeto J (2009) Long-term effects of pallidal or subthalamic deep brain stimulation on quality of life in Parkinson's disease. Mov Disord 24(8):1154-1161

21. Ferraye M, Debu B, Fraix V, Xie-Brustolin J, Chabardès S, Krack P, AL Benabid, Pollak P (2008) Effects of subthalamic nucleus stimulation and levodopa on freezing of gait in Parkinson disease. Neurology 70:1431-1437

22. Guo X, Gao G, Wang X, Li L, Liang Q, Zhang H (2008) Effects of bilateral deep brain stimulation of the subthalamic nucleus on olfactory function in Parkinson's disease patients. Stereotact Funct Neurosurg 86:237-244

23. Montel S, Bungener C (2008) What relation is there between deep brain stimulation and coping strategies in Parkinson's disease? Mov Disord 23(12):1780-1787
24. Moro E, Volkmann J, Konig I, Winkler S, Hiller A, Hassin-Baer $S$ et al (2008) Bilateral subthalamic stimulation in Parkin and PINK1 Parkinsonism. Neurology 70:1186-1191

25. York M, Dulay M, Macias A, Levin HS, Grossman R, Simpson R, Jankovic J (2008) Cognitive declines following bilateral subthalamic nucleus deep brain stimulation for the treatment of Parkinson's disease. J Neurol Neurosurg Psychiatry 79:789-795

26. Cilia R, Siri C, Marotta G, De Gaspari D, Landi A, Mariani CB, Benti R, Isaias IU, Vergani F, Pezzoli G, Antonini A (2007) Brain networks underlining verbal fluency decline during STN-DBS in Parkinson's disease: an ECD-SPECT study. Park Rel Disord 13:290-294

27. Lokkegaard A, Werdelin L, Regeur L, Karlsborg M, Jensen SR, Brødsgaard E, Madsen FF, Lonsdale MN, Friberg L (2007) Dopamine transporter imaging and the effects of deep brain stimulation in patients with Parkinson's disease. Eur J Nucl Med Mol Imaging 34:508-516

28. Lyons KE, Davis J, Pahwa R (2007) Subthalamic nucleus stimulation in Parkinson's disease patients intolerant to levodopa. Stereotact Funct Neurosurg 85:169-174

29. Piboolnurak P, Lang AE, Lozano AM, Miyasaki JM, Saint-Cyr JA, Poon YY, Hutchison WD, Dostrovsky JO, Moro E (2007) Levodopa response in long-term bilateral subthalamic stimulation for Parkinson's disease. Mov Disord 22(7):990-997

30. Tabbal S, Revilla F, Mink JW, Schneider-Gibson P, Wernie AR, de Erausquin GA, Perlmutter JS, Rich KM, Dowling JL (2007) Safety and efficacy of subthalamic nucleus deep brain stimulation performed with limited intraoperative mapping for treatment of Parkinson's disease. Neurosurgery 61:119-127 (discussion 127-129)

31. Tsai S-T, Lin S-H, Lin S-Z, Chen J-Y, Lee C-W, Chen S-Y (2007) Neuropsychological effects after chronic subthalamic stimulation and the topography of the nucleus in Parkinson's disease. Neurosurgery 61:1024-1030

32. Valldeoriola F, Morsi O, Tolosa E, Rumia J, Marti M, MartinezMartin P (2007) Prospective comparative study on cost-effectiveness of subthalamic stimulation and best medical treatment in advanced Parkinson's disease. Mov Disord 22(15):2183-2191

33. De Gaspari D, Siri C, Landi A, Cilia R, Bonetti A, Natuzzi F, Morgante L, Mariani CB, Sganzeria E, Pezzoli G, Antonini A (2006) Clinical and neuropsychological follow up at 12 months in patients with complicated Parkinson's disease treated with subcutaneous apomorphine infusion or deep brain stimulation of the subthalamic nucleus. J Neurol Neurosurg Psychiatry 77: $450-453$

34. Østergaard K, Sunde N (2006) Evolution of Parkinson's disease during 4 years of bilateral deep brain stimulation of the subthalamic nucleus. Mov Disord 21(5):624-631

35. Fraix V, Houeto JL, Lagrange C, Le Pen C, Krystkowiak P, Guehl D, Ardouin C et al (2006) Clinical and economic results of bilateral subthalamic nucleus stimulation in Parkinson's disease. J Neurol Neurosurg Psychiatry 77:443-449

36. Lubik S, Fogel W, Tronnier V, Krause M, Konig J, Jost W (2006) Gait analysis in patients with advanced Parkinson's disease: different or additive effects on gait induced by levodopa and chronic STN stimulation. J Neural Transm 113:163-173

37. Smeding H, Speelman J, Konig-Haanstra M, Schuurman PR, Nijssen P, van Laar T, Schmand B (2006) Neuropsychological effects of bilateral STN stimulation in Parkinson disease. A controlled study. Neurology 66:1830-1836

38. Capecci M, Ricciuti RA, Burini D, Bombace VG, Provinciali L, Iacoangeli M, Scerrati M, Ceravolo MG (2005) Functional improvement after subthalamic stimulation in Parkinson's disease: a non-equivalent controlled study with 12-24 month follow up. J Neurol Neurosurg Psychiatry 76:769-774

39. Nilsson M, Tornqvist A, Rehncrona S (2005) Deep brain stimulation in the subthalamic nuclei improves balance performance in 
patients with Parkinson's disease, when tested without anti-parkinsonian medication. Arch Neurol Scand 111:301-308

40. Alegret M, Valldeoriola F, Marti M, Pilleri M, Junque C, Rumia J, Tolosa E (2004) Comparative cognitive effects of bilateral subthalamic stimulation and subcutaneous continuous infusion of apomorphine in Parkinson's disease. Mov Disord 19(12):14631469

41. Visser-Vandewalle V, van der Linden C, Temel Y, Celik A, Ackermans L, Spincemaille G, Caemaert J (2004) Long-term effects of bilateral subthalamic nucleus stimulation in advanced Parkinson disease: a four year follow-up study. Park Rel Disord $11: 157-165$

42. Jaggi J, Umemura A, Hurtig H, Siderowf AD, Colcher A, Stern MB, Baltuch GH (2004) Bilateral stimulation of the subthalamic nucleus in Parkinson's disease: surgical efficacy and prediction of outcome. Stereotact Funct Neurosurg 82:104-114

43. Rodriguez-Oroz M, Zamarbide I, Guridi J, Palmero M, Obeso J (2004) Efficacy of deep brain stimulation of the subthalamic nucleus in Parkinson's disease 4 years after surgery: double-blind and open label evaluation. $\mathrm{J}$ Neurol Neurosurg Psychiatry 75:1382-1385

44. Russman H, Ghika J, Villemure J-G, Robert B, Bogousslavsky J, Burkhard PR, Vingerhoets FJ (2004) Subthalamic nucleus deep brain stimulation in Parkinson disease patients over 70 years. Neurology 63:1952-1954

45. Russman H, Ghika J, Combrement P, Vellemure JG, Bogousslavsky J, Burkhard PR, Vingerhoets FJ (2004) L-Dopa-induced dyskinesia improvement after STN-DBS depends upon medication reduction. Neurology 63:153-155

46. Gironell A, Kulisevsky J, Rami L, Fortuny N, Garcia-Sanchez C, Pascual-Sedano B (2003) Effects of pallidotomy and bilateral subthalamic stimulation on cognitive function in Parkinson disease. A controlled comparative study. J Neurol 250:917-923

47. Krack P, Batir A, Van Blercom N, Chabardes S, Fraix V, Ardouin C, Koudsie A, Limousin PD, Benazzouz A, LeBas JF, Benabid AL, Pollak P (2003) Five-year follow-up of bilateral stimulation of the subthalamic nucleus in advanced Parkinson's disease. N Engl J Med 349:1925-1934

48. Tamma F, Rampini P, Egidi M, Caputo E, Locatelli M, Pesenti A, Chiesa V, Ardolino G, Foffani G, Meda B, Pellegrini M, Priori A (2003) Deep brain stimulation for Parkinson's disease: the experience of the Policlinico-San Paolo Group in Milan. Neurol Sci 24:S41-S42

49. Iansek R, Rosenfeld J, Huxham F (2002) Deep brain stimulation of the subthalamic nucleus in Parkinson's disease. MJA 177:142-146

50. Just H, Ostergaard K (2002) Health-related quality of life in patients with advanced Parkinson's disease treated with deep brain stimulation of the subthalamic nuclei. Mov Disord 17(3):539-545

51. Ostergaard K, Sunde N, Dupont E (2002) Effects of bilateral stimulation of the subthalamic nucleus in patients with severe Parkinson's disease and motor fluctuations. Mov Disord 17:693700

52. Simuni T, Jaggi J, Mulholland H, Hurtig HI, Colcher A, Siderowf AD, Ravina B, Skolnick BE, Goldstein R, Stern MB, Baltuch GH (2002) Bilateral stimulation of the subthalamic nucleus in patients with Parkinson disease: a study of efficacy and safety. J Neurosurg 96:666-672

53. Welter ML, Houeto JL, Tezenas du Montcel S, Mesnage V, Bonnet AM, Pillon B, Arnulf I, Pidoux B, Dormont D, Cornu P, Agid Y (2002) Clinical predictive factors of subthalamic stimulation in Parkinson's disease. Brain 125(Pt 3):575-583

54. Perozzo P, Rizzone M, Bergamasco B, Bergamasco B, Castelli L, Lanotte M, Tavella A, Torre E, Lopiano L (2001) Deep brain stimulation of the subthalamic nucleus in Parkinson's disease: comparison of pre- and postoperative neuropsychological evaluation. J Neurol Sci 192:9-15

55. Deep-Brain Stimulation for Parkinson's Disease Study Group (2001) Deep-brain stimulation of the subthalamic nucleus or the pars interna of the globus pallidus in Parkinson's disease. N Engl J Med 345(13):956-963

56. Houeto JL, Damier P, Bejjani PB, Staedler C, Bonnet AM, Arnulf I, Pidoux B, Dormont D, Cornu P, Agid Y (2000) Subthalamic stimulation in Parkinson's disease: a multidisciplinary approach. Arch Neurol 57:461-465

57. Pillon B, Ardouin C, Damier P, Krack P, Houeto JL, Klinger H, Bonnet AM, Pollak P, Benabid AL, Agid Y (2000) Neuropsychological changes between "off" and "on" STN or GPi stimulation in Parkinson's disease. Neurology 55:411-418

58. Morgante L, Basile G, Epifanio A, Spina E, Antonini A, Stocchi F, Di Rosa E, Martino G, Marconi R, La Spina P, Nicita-Mauro V, Di Rosa AE (2004) Continuous apomorphine infusion (CAI) and neuropsychiatric disorders in patients with advanced Parkinson's disease: a follow-up of two years. Arch Gerontol Geriatr Suppl 9:291-298

59. Di Rosa A, Epifanio A, Antonini A, Stocchi F, Martino G, Di Blasi L, Tetto A, Basile G, Imbesi D, La Spina P, Di Raimondo G, Morgante L (2003) Continuous apomorphine infusion and neuropsychiatric disorders: a controlled study in patients with advanced Parkinson's disease. Neurol Sci 24:174-175

60. Pietz K, Hagell P, Odin P (1998) Subcutaneous apomorphine in late stage Parkinson's disease: a long-term follow-up. J Neurol Neurosurg Psychiatry 65:709-716

61. Elia A, Dollenz C, Soliveri P, Albanese A (2012) Motor features and response to oral levodopa in patients with Parkinson's disease under continuous dopaminergic infusion or deep brain stimulation. Eur J Neurol 19:76-83

62. van Laar T, Postma A, Drent M (2010) Continuous subcutaneous infusion of apomorphine can be used safely in patients with Parkinson's disease and pre-existing visual hallucinations. Park Rel Disord 16:71-72

63. Garcia Ruiz P, Sesar Ignacia A, Ares Pensado B, Castro Garcia A, Alonso Frech F, Alvarez Lopez M et al (2008) Efficacy of long-term continuous subcutaneous apomorphine infusion in advanced Parkinson's disease with motor fluctuations: a multicenter study. Mov Disord 23(8):1130-1136

64. Katzenschlager R, Hughes A, Evans A, Manson AJ, Hoffman M, Swinn L, Watt H, Bhatia K, Quinn N, Lees AJ (2005) Continuous subcutaneous apomorphine therapy improves dyskinesias in Parkinson's disease: a prospective study using single-dose challenges. Mov Disord 20(2):151-157

65. Tyne H, Parsons J, Sinnott A, Fox S, Fletcher N, Steiger M (2004) A 10 year retrospective audit of long-term apomorphine use in Parkinson's disease. J Neurol 251:1370-1374

66. Manson A, Turner K, Lees A (2002) Apomorphine monotherapy in the treatment of refractory motor complications of Parkinson's disease: long-term follow-up study of 64 patients. Mov Disord 17(6):1235-1241

67. Stocchi F, Vacca L, De Pandis M, Barbato L, Valente M, Ruggieri S (2001) Subcutaneous continuous apomorphine infusion in fluctuating patients with Parkinson's disease: long-term results. Neurol Sci 22:93-94

68. Colzi A, Turner K, Lees A (1998) Continuous subcutaneous waking day apomorphine in the long-term treatment of levodopa induced interdose dyskinesias in Parkinson's disease. J Neurol Neurosurg Psychiatry 64:573-576

69. Hughes A, Bishop S, Kleedorfer B, Turjanski N, Fernandez W, Lees AJ, Stern GM (1993) Subcutaneous apomorphine in Parkinson's disease: response to chronic administration for up to 5 years. Mov Disord 8(2):165-170 
70. Ellis C, Lemmens G, Parkes J, Abbott RJ, Pye IF, Leigh PN, Chaudhuri KR (1997) Use of apomorphine in Parkinsonian patients with neuropsychiatric complications to oral treatment. Park Rel Disord 3(2):103-107

71. Nyholm D, Nilsson Remahl A, Dizdar N, Constantinescu R, Holmberg B, Jansson R, Aquilonius SM, Askmark H (2005) Duodenal levodopa infusion monotherapy vs oral polypharmacy in advanced Parkinson's disease. Neurology 64:216-223

72. Olanow C, Antonini A, Kieburtz K et al (2012) Randomized, double-blind, double-dummy study of continuous infusion of levodopa-carbidopa intestinal gel in patients with advanced Parkinson's disease: efficacy and safety. Abstract presented at the AAN 64th Annual Meeting, 21-28 April 2012

73. Nyholm D, Askmark H, Gomes-Trolin C, Knutson T, Lennermas H, Nystrom C, Aquilonius SM (2003) Optimizing levodopa pharmacokinetics: intestinal infusion versus oral sustainedrelease tablets. Clin Neuropharmacol 26(3):156-163

74. Merola A, Zibetti M, Angrisano S, Rizzi L, Lanotte M, Lopiano L (2011) Comparison of subthalamic nucleus deep brain stimulation and duodopa in the treatment of advanced Parkinson's disease. Mov Disord 26(4):664-670

75. Devos D, French DUODOPA Study Group (2009) Patient profile, indications, efficacy and safety of duodenal levodopa infusion in advanced Parkinson's disease. Mov Disord 24(7):993-1000

76. Honig H, Antonini A, Martinez-Martin P, Forgacs I, Faye GC, Fox T, Fox K, Mancini F, Canesi M, Odin P, Chaudhuri KR (2009) Intrajejunal levodopa infusion in Parkinson's disease: a pilot multicenter study of effects on nonmotor symptoms and quality of life. Mov Disord 24(10):1468-1474

77. Antonini A, Mancini F, Canesi M, Zangaglia R, Isaias IU, Manfredi L, Pacchetti C, Zibetti M, Natuzzi F, Lopiano L, Nappi G, Pezzoli G (2008) Duodenal levodopa infusion improves quality of life in advanced Parkinson's disease. Neurogener Dis $5: 244-246$
78. Eggert K, Schrader C, Hahn M, Stamelou M, Russmann A, Dengler R, Oertel W, Odin P (2008) Continuous jejunal levodopa infusion in patients with advanced Parkinson disease: practical aspects and outcome of motor and non-motor complications. Clin Neuropharmacol 31(3):151-166

79. Nyholm D, Lewander T, Johansson A, LeWitt P, Lundqvist C, Aquilonius S-M (2008) Enteral levodopa/carbidopa infusion in advanced Parkinson disease: long-term exposure. Clin Neuropharmacol 31(2):63-73

80. Nilsson D, Nyholm D, Aquilonius S-M (2001) Duodenal levodopa infusion in Parkinson's disease-long-term experience. Acta Neurol Scand 104:343-348

81. Syed N, Murphy J, Zimmerman T, Mark M, Sage J (1998) Ten years' experience with enteral levodopa infusions for motor fluctuations in Parkinson's disease. Mov Disord 13(2):336-338

82. Nyholm D, Jansson R, Willows T, Remahl I (2005) Long-term 24-hour duodenal infusion of levodopa-outcome and dose requirements. Neurology 65(9):1506-1507

83. Voges J, Hilker R, Botzel K, Kiening K, Kloss M, Kupsch A (2007) Thirty days complication rate following surgery performed for deep-brain stimulation. Mov Disord 22(10):1486-1489

84. Schüpbach WM, Gargiulo M, Welter ML, Mallet L, Behar C, Houeto JL, Maltete D, Mesnage V, Agid Y (2006) Neurosurgery in Parkinson disease: a distressed mind in a repaired body? Neurology 66(12):1811-1816

85. Kempster P, Williams D, Selikhova M, Holton J, Revesz T, Lees A (2007) Patterns of levodopa response in Parkinson's disease: a clinico-pathological study. Brain 130:2123-2128

86. Muslimovic D, Post B, Speelman J, de Haan R, Schmand B (2009) Cognitive decline in Parkinson's disease: a prospective longitudinal study. J Int Neuro Soc 15:426-437

87. Gallagher D, Lees A, Schrag A (2010) What are the most important nonmotor symptoms in patients with Parkinson's disease and are we missing them? Mov Disord 25(15):2493-2500 